\title{
The Packaging Industry and Sustainability
}

\author{
By David Hillier ${ }^{\dagger}$ \\ Daphne Comfort \\ Peter Jones*
}

The aim of this paper is to offer an exploratory review of the sustainability agendas and achievements reported by the leading global companies within the packaging industry. The paper begins with brief outlines of corporate sustainability and the growing interest in sustainability reporting and of the packaging industry and the empirical material for the paper is drawn from the most recent sustainability reports posted on the packaging companies' corporate websites. The findings reveal that while the leading packaging companies recognised the impacts their businesses have on the environment, on society and to a lesser extent on the economy, there are variations in the character, extent and detail of the sustainability reporting process. That said, the sustainability reports included details of a wide range of environmental, social and economic issues but more generally the reports had a number of weaknesses that, at least partly, undermine their transparency and credibility. The authors also argue that the leading packaging companies' definitions of, and commitments to, sustainability are principally driven by business imperatives rather than any fundamental concern to maintain the viability and integrity of natural and social capital. More critically, the authors argue that this approach is couched within existing business models centred on continuing growth and consumption. The paper provides an accessible review of current approaches to sustainability in the global packaging industry and as such it will interest professionals working in the industry and its supply chain as well as academics and students interested in business strategy and sustainability.

Keywords: global packaging industry: corporate sustainability; sustainability reporting; environment; society; assurance; materiality.

\section{Introduction}

Packaging is an important component of many facets of modern consumption in that it has become part of the delivery system for products and it is generally seen to fulfil four key functions, namely to 'preserve and protect the product', 'to communicate brand image', to 'convey information', and 'offer convenience' (PricewaterhouseCoopers 2010, p.4). At the same time packaging materials require the use of a wide range of natural resources whose disposal

\footnotetext{
${ }^{\dagger}$ Professor David Hillier died following a short illness after the completion of the initial version of this paper. For many years he was Head of Geography at the University of South Wales and latterly an Emeritus Professor in the University's Centre for Police Sciences. His research interests were in urban design, sustainability and retailing.

${ }^{*}$ Research Administrator, Business School, University of Gloucestershire, Cheltenham, UK.

* Professor of Management, Business School, University of Gloucestershire, Cheltenham, UK.
} 
has a direct impact on the environment and widespread concerns have been expressed about the negative environmental impact of packaging systems. In outlining the environmental impact of paper based packaging, for example, Michael Warner, a Senior Resource Campaigner at Friends of the Earth, argued that 'each stage of production - forestry, pulping, processing and printing has associated environmental and human impacts' (Raconteur 2013, webpage). More specifically, Warner argued that 'the production process takes its toll' in that 'transforming wood from trees into thin uniform paper products requires the intensive use of wood, energy and chemicals' and that 'clearing forests for packaging also worsens climate change' (Raconteur 2013, webpage). While PricewaterhouseCoopers (2010, p. 18) suggested that 'the packaging industry is fragmented over sustainable packaging and, to date, has been a poor case for the essential nature of it products', the packaging industry has claimed that 'packaging clearly contributes to sustainability by limiting product waste and over production' (Europen 2011, p. 5). Nevertheless PricewaterhouseCoopers (2010, p. 18) argued that 'unless the industry becomes more proactive in the debate about the definition and role of sustainable packaging, it runs the risk of packaging continuing to receive disproportionate attention for its environmental impact.' With this in mind the aim of this paper is to offer an exploratory review of the sustainability agendas and achievements reported by the leading global companies within the packaging industry. The paper begins with brief outlines of corporate sustainability and the growing interest in sustainability reporting and of the packaging industry. This is followed by a review of the most recently published sustainability reports from the leading global packaging companies and the paper concludes by offering some reflections on current approaches to sustainability within the packaging industry.

\section{Corporate Sustainability and Sustainability Reporting}

The ideas underpinning sustainability are not new (e. g. Gruber 2013) but the concept began to attract increasing attention from the 1980s onwards following the publication of the 'World Conservation Strategy' (International Union for Conservation of Nature and Natural Resources 1980) and 'Our Common Future' (World Commission on Environment and Development 1987). Diesendorf (2000) argued that sustainability can be seen as the goal of the process of sustainable development. Arguably the most widely used definition of sustainable development is that provided in 'Our Common Future' namely 'development that meets the needs of the present without compromising the ability of future generations to meet their own needs' (World Commission on Environment and Development 1987, webpage). However defining sustainability is not straight forward and it 'means different things to different people' (Aras and Crowther 2008, p.436). There is a family of definitions essentially based in and around ecological principles and there are definitions which include social and economic development as well as environmental goals and which look to embrace equity in meeting human needs. 
More critically Hudson (2005, p.241) argued that definitions range from 'pallid blue green to dark deep green.' The former Hudson (2005, p.241) suggests centre on 'technological fixes within current relations of production, essentially trading off economic against environmental objectives, with the market as the prime resource allocation mechanism' while for the latter 'prioritizing the preservation of nature is pre-eminent.' Hudson (2005, p.241) also suggests that the dominant view of sustainability is grounded in a blue-green discourse of ecological modernization' and 'claims that capital accumulation, profitable production and ecological sustainability are compatible goals.' Further he contrasts this view with the 'deep green' perspective which 'would require significant reductions in living standards and radical changes in the dominant social relations of production.' In a similar vein a distinction is often made, for example, between 'weak' and 'strong' sustainability and Roper (2012, p.72) suggests that 'weak sustainability prioritizes economic development, while strong sustainability subordinates economies to the natural environment and society, acknowledging ecological limits to growth.'

As investors, consumers, governments, interests groups and the media have become more acutely aware about the environmental, social and economic impacts of business activities so corporate sustainability initiatives have assumed ever increasing importance. KPMG (2012, webpage), for example, suggested that 'the evidence that sustainability is becoming a core consideration for successful businesses around the world grows stronger every day.' While there is broad agreement that corporate sustainability is concerned with environmental, social and economic issues and with governance, there is little consensus in defining the term and a number of meanings can be identified. There are definitions which seem to emphasise business continuity. Dyllick and Hockerts (2002, p13), for example, define corporate sustainability as 'meeting the needs of a firm's direct and indirect shareholders....... without compromising its ability to meet the needs of future stakeholders as well.' There are also definitions that look to include environmental and social goals and to formally incorporate these goals into corporate strategy. van Marrewijk and Werre (2002, p. 107), for example, argued that 'corporate sustainability refers to a company's activities - voluntary by definition - demonstrating the inclusion of social and environmental concerns.' In some ways Amini and Bienstock (2014, p.13) combined both approaches and argued that corporate sustainability 'embraces the idea that an organization, in order to remain fundamentally sustainable in the long term, must consider all of the contexts in which it is embedded: economic, social and environmental.'

More generally corporate sustainability is also increasingly seen to incorporate the more recently developed concept of the creation of shared value. This concept has been 'defined as policies and practices that enhance the competitiveness of a company while simultaneously addressing the economic and social conditions in the communities in which it operates'(Porter and Kramer 2011, p. 78). Essentially Porter and Kramer (2011) suggested that the purpose of the corporation had to be redefined as creating economic values in a way that also creates value for society by addressing its challenges and needs and the concept has been adopted by a small but growing group of large companies. Nestle (2017, 
webpage), for example, claimed that looking to the future creating shared value remains a fundamental guiding $g$ principle of how we do business' and that 'our positive impact on society focuses on enabling healthier and happier lives for individuals and families, on helping the development of thriving and resilient communities and, finally, on stewarding the planet's natural resources for future generations.'

In many ways sustainability, corporate sustainability and the creation of shared value all share a common, if competing, set of theoretical underpinnings. Garriga and Mele (2004, p. 51), identified four groups of theories, namely instrumental theories, political theories, integrative theories and ethical theories, based on 'ethical responsibilities of corporations to society.' Further Garriga and Mele (2004) suggested that in practice, each theory presents four dimensions related to profits, political performance, social demands and ethical values. More recently, Lozano et al. (2015) have reviewed how a wide range of theories of the firm have contributed to corporate sustainability, but suggested that each of these theories is limited in that they each address specific dimensions of sustainability. The authors concluded by proposing a new theory which, they argued, provides corporations and their stakeholders with a more complete vision of their obligations, opportunities, relations and processes in 'helping to make societies more equitable and sustainable in the short and long term' (Lozano 2015, p. 430).

In some ways sustainability reporting has become an 'industry' in itself and a number of private companies and voluntary organisations offer sustainability reporting services and frameworks. The United Nations Environment Programme (2013, p.21), for example, identified a number of 'reporting frameworks and protocols, reporting systems, standards and guidelines' but argued that the Global Reporting Initiative 'has become the leading global framework for sustainability reporting' and cited its comprehensive scope, its commitment to continuous improvement and its consensus approach as being important in contributing to its pre-eminence in the field. Originally founded in 1997, the Global Reporting Initiative reporting framework has progressively evolved from the original G1 Guidelines launched in 2000 into the current G4 Guidelines introduced in 2013. Within the current G4 Guidelines, materiality and external assurance are seen to be of central importance. Materiality is concerned with who is involved in identifying the environmental, social and economic issues that matter most to a company and its stakeholders and how this process is undertaken. External assurance is a procedure employed to provide confidence in both the accuracy and the reliability of the reporting process.

More generally, the growth in corporate sustainability reporting and an increasing focus on materiality and external assurance in the reporting process all reflect calls for greater transparency within sustainability reporting. Sustainability (2014, p.10) defined 'effective corporate transparency' as being 'when a company provides or makes available appropriate and timely information to all relevant stakeholders with the intention of optimizing decision making that leads to more sustainable decisions.' In many ways transparency can be seen as the key to sustainability in that 'once a company makes a commitment to transparency, 
the rest must follow' (CSR Reporting 2011, webpage). Looking to the future, greater transparency can be seen to be crucial in creating the momentum within companies to actively address environmental and social impacts and challenges and more generally in driving corporate performance.

\section{The Packaging Industry}

Packaging plays a vital role in the protection, storage and hygienic handling of products. In the food industry, for example, packaging provides protection against damage and contamination by micro-organisms, air, water and toxins. Packaging encompasses a wide range of materials including paper, board, plastic, metal, glass and wood. Originally packaging began with natural products, such as leaves, later woven materials and pots were used to package products and it is estimated that wood and glass packaging have been used for 5,000 years. The use of metal for packaging dates from the early nineteenth century, though conventional cans were not used until the twentieth century and while paper and cardboard were increasingly widely used from 1900 onwards, plastic packaging became much more widespread in the second half of the twentieth century (ASD 2013).Today paper and board account for some $40 \%$ of the market with plastics accounting for a further $30 \%$.

While packaging fulfils a number of functions. Its role in protecting product integrity is particularly important in the food industry, for example, in that packaging is important in protecting food stuffs from discolouration, disfigurement or oxidation due to direct exposure to sunlight, germs, bacteria and dust and in helping to reduce waste within the food supply chain. Packaging has also long been important in facilitating the transport of materials. Traditionally, traders and shopkeepers would buy many foodstuffs in bulk and then put them into smaller bags to re-sell them to customers who would use the bags to carry them home. Increasingly within contemporary society, packaging has become important to improve efficiency in transport and distribution by reducing the costs involved in storage and handling, while providing shelf-ready packaging to enable retailers to maximize the number of products on display and to reduce restocking time and often in enabling customers to consume products at their convenience. Packaging also plays a vital role in conveying a wide range of product information to customers, including information on use by dates, ingredients and health and safety. Packaging is also seen to be vitally important marketing tool in that it is seen to enhance product appeal, to create and enhance brand awareness and to influence consumer buying behaviour.

The global packaging market has an estimated annual turnover of some US\$ 500 billion (Persistence Market Research 2015) with consumer goods packaging accounting for $80 \%$ of this figure (EY 2013). Geographically, EY (2013) estimated that in 2012 Europe accounted for 34\% of the global packaging market, as did Asia, the Middle East and Africa, while the corresponding figures for North America and Africa were 27\% and $4 \%$ respectively. EY (2013) further estimated that food products and beverages accounted for $69 \%$ of all end market 
packaging while the corresponding figures for other consumer goods, cosmetics and health care were $20 \%, 6 \%$ and $5 \%$ respectively. The companies that produce packaging convert commodity raw materials, such as paper, board and polymer, into consumer or industrial packaging. The raw material supply companies are typically large global producers and while this element of the supply chain is highly concentrated, the packaging production industry is much more fragmented.

That said there are a number of leading players within the global packaging market and while some of them concentrate on one type of packaging others manufacture a range of packaging products. International Paper, for example, the world's largest packaging company, produces fibre based packaging, pulp and paper. The company has its headquarters in Memphis, Tennessee, US, employs 55,000 people worldwide and has manufacturing plants in 24 countries. In 2014 it generated revenues of US \$23 billion. Westrock has 42,000 employees in some 30 countries; Smurfit Kappa, an Irish based company with 45,000 employees; Mondi, which is headquartered in Vienna, Austria, employs 24,000 people across 30 countries; and Stora Enso, which is based in Helsinki, Finland and has the majority of its manufacturing operations within Europe; are all paper based packaging companies. Ball Corporation is a US based company that produces metal beverage and food packaging, metal food and household products packaging and extruded aluminum packaging, has 15,000 employees and while its manufacturing plants are concentrated in both North and South America and Europe the company also has a presence in Asia, the Middle East and Africa. Crown Holdings, which is headquartered in Philadelphia, US and employs some 22,000 people, manufactures metal beverage and food cans and metal aerosol containers, while Sealed Air, a US based company with 25,000 employees, specialises in vacuum shrink packaging and bubble wrap cushioning.

A variety of factors have been identified as driving change within the packaging industry including the levels of economic activity; demographic trends including the ageing of the world's population; changing lifestyles; including the growth in the numbers of both women in full time employment and in single person households; competition between retailers and the search for ever more efficient retail business models; increasing health awareness; stricter regulatory and legislative frameworks; developments in Information and communication technologies; and growing environmental awareness. This last factor recognises that the packaging industry has been increasingly cast in an often unfavourable light because it is perceived to have a damaging impact on the environment. That said the packaging industry is keen to emphasise the positive impact it has on the environment in that it reduces the use of natural resources by reducing waste and that the environmental impact of packaging waste can be reduced through the prudent choice of packaging materials and by recycling.

\section{Frame of Reference and Method of Enquiry}

In an attempt to obtain an exploratory review of how the packaging industry is publicly addressing and reporting on its sustainability strategies and 
achievements the top ten global companies (as measured by revenue), namely International Paper, Westrock, Stora Enso, Reynolds Group., Amcor, Smurfit Kappa, Crown Holdings, Ball Corporation, Mondi and Sealed Air, (Technavio 2016)) were selected for study. As the leading players within the packaging industry the selected companies might be seen to reflect contemporary approaches to sustainability in the sector and be keen to publicise their sustainability initiatives to a wide audience. Increasingly large companies employ the Internet to report on their sustainability strategies and achievements. This led the authors to conduct a digital Internet search for information, using the key phrase 'sustainability report' and the name of each of the selected packaging companies. This search was undertaken in April 2017, employing Google as the search engine, and the most recent information obtained via this search formed the empirical material for this paper.

A number of authors (e. g. Guthrie and Abeysekera 2006, Newell 2008, and de Grosbois 2016) have used content analysis to systematically identify features within sustainability reports on corporate websites. However, the authors looked to base their current commentary on the reading and reflective review of the selected reports and in taking this decision they were mindful that only a relatively small number of reports were being reviewed and that these reports were well structured and signposted and thus a detailed systematic analysis was not appropriate for the current exploratory study. The information from the reading and review process provided the empirical information for this commentary paper. The aim is not to offer a systematic and detailed comparative analysis and evaluation of the selected companies' approaches to sustainability and the specific examples and quotations are employed primarily for illustrative rather than comparative purposes. Unless specifically cited all quotations are drawn from the selected companies' sustainability reports. The paper is based on information that is in the public domain and the authors took the considered view that they did not need to contact the selected companies to obtain formal permission prior to conducting their research.

When outlining the issues of reliability and validity in relation to information on the Internet, Saunders et.al. (2009) emphasised the importance of the authority and reputation of the source and the citation of a specific contact individual who can be approached for additional information. In reviewing the sustainability reports the authors felt that the two conditions were met. At the same time the authors recognise that the approach chosen has its limitations in that there are issues in the extent to which a company's public statements fulsomely, and in detail, reflect strategic corporate thinking and whether or not such pronouncements might be considered little more than carefully constructed public relation exercises. However, the authors believe that their approach offers a suitable approach for the current exploratory study. 


\section{Findings}

The findings revealed that eight of the selected packaging companies, namely International Paper, Westrock, Amcor, Smurfit Kappa, Crown Holdings, Ball Corporation, Mondi and Sealed Air, published dedicated sustainability reports and Stora Enso produced a sustainability report as part of its annual report. Alcoa, the parent company which acquired Reynolds Group's brand name and its packaging and consumer products businesses in 2000, posted some limited information on its approach to sustainability. Two sets of themes, namely (i) the environmental, social and economic issues about which the selected packaging companies report and provide information on sustainability and (ii) the nature of the reporting process, merit attention.

Firstly, the majority of the selected companies emphasised their corporate concern for, and commitment to, sustainability. The International Paper Group, for example, emphasised its 'commitment to the highest ethical and sustainability standards is guided by a basic principle: do the right things for the right reasons. This affects everything we do - from employee and community engagement, to our use of natural resources and our commitment to forest stewardship, to our impact on the planet.' In a similar vein the Ball Corporation claim to 'have embedded sustainability into our strategic planning', to 'build sustainability goals from the bottom up' and to 'strive to put the right people, processes and partners in place to help us to create long term shared value and to achieve our sustainability goals.' In his introductory message to his company's report Ron Delta, Chief Executive Officer of Amcor, stressed that 'leadership in the global packaging industry includes accountability for helping to reduce the environmental and social effects of our business.' In 'A Message from Our Leadership' John W. Conway and Timothy, J. Donohue, the Chairman and President of Crown Holdings, argued 'to be successful sustainability must be integrated into every aspect of a company' and claimed that 'this is how we view sustainability here at Crown.'

Some of the leading packaging companies explicitly identified a number of strategic priorities. Within its sustainability strategy International Paper, for example, identified 'six strategic focus areas' namely safety; stakeholder engagement; ethics and compliance; forest stewardship; greenhouse gas emissions; and water use. The company stressed its belief that 'a sharp focus' on these areas 'will help us continue to move in the right direction on some of the most critical issues for our company and the communities in which we operate.' The company stressed, for example, that 'ethical behaviour and personal integrity are at the core of our culture' and that 'these values extend beyond our employees to our suppliers, who are required to maintain the same level of ethics and integrity in their dealings with us.' In a similar vein Smurfit Kappa identified 'five strategic sustainability priorities' namely forest management; climate change; water management; waste management; and people. Smurfit Kappa also stressed its commitment to 'designing our operations around a circular economy model' in which 'the productivity of the 
resources we use is maximised and waste, including carbon dioxide emissions, is minimised.'

More generally the selected packaging companies evidenced their strategic commitment to sustainability across a wide range of environmental, social and economic agendas. A number of environmental issues were addressed including climate change and greenhouse gas emissions, energy efficiency, sustainable forest management, water management and waste management and recycling, Smurfit Kappa, for example, recognised that 'the production and use of fossil energy is one of the major contributors to greenhouse gas emissions and climate change globally', that 'paper production is energy intensive' and that 'our industry's challenge is to reduce the energy intensity of production.' More specifically the company reported a reduction of $22.6 \%$ in its relative fossil carbon dioxide emissions from its paper and board mills between 2005 and 2015 and a 10\% improvement in the energy usage per tonne of paper produced at its mills during the same time period. Westrock reported having established a goal to reduce greenhouse gas emissions from its manufacturing facilities by $20 \%$ in the ten years up to 2025 .

A number of the selected packaging companies reported on the energy efficiency initiatives and on the development of renewable and alternative energy sources. Ball Corporation, for example, reported focusing on six energy efficiency areas namely employee engagement; machinery and equipment; heating and cooling; heat recovery; lighting; and energy management. More generally the company reported investing $\$ 32$ million dollars in energy saving projects in 2014 and 2015 which led to electricity savings of 79 million kilowatts per annum and natural gas savings of 105 kilowatts per annum. International Paper reported on a project at its coated paperboard mill at Augusta in the US, which enables the mill to reuse heat captured in water used to cool plant equipment, and to use it to generate hot water elsewhere in the plant. Westrock reported that 'a key element in our strategy to reduce greenhouse gases is leveraging what we do best - using biomass.' More specifically the company reported that its integrated kraft paper mills, which are its most energy intensive manufacturing facilities, burn renewable biomass to generate $60 \%$ of their energy needs.

Forest and plantation management is an important theme for those companies which specialise in producing paper and paper based packaging. Stora Enso, for example, emphasised that 'sustainable forest management is in our immediate and long term interest, as it keeps forests healthy and productive, and thus helps secure the long-term availability of the renewable resources we use.' The company claimed that its 'policy on wood and fibre sourcing covers the entire cycle of forest and plantation management' and that 'compliance with national legislation is only the starting point for our work' which also includes supporting and implementing 'voluntary forest conservation and restoration measures' 'tree breeding', designed, for example, to improve the productivity and quality of eucalyptus trees grown on company plantations and participation in 'numerous local and global forestry associations, networks and programmes.' Smurfit Kappa which produces paper from both virgin and recycled fibres, reported on its 
approach to sustainably sourcing fibres at its plantations and forestry operations. The company argued that 'we believe forests can supply sufficient quantities of sustainable, renewable sources of fibre when managed well' and claimed that 'everything we do is subject to strict principles of sustainability and the highest standards of practice to ensure sustainable forest management.' That said the company recognised, that globally forest areas are decreasing and that continuing deforestation is a growing concern for stakeholders and that wood fibres cannot be endlessly recycled but suggested that research was required to extend the lifespan of fibres.

Water management is an important issue for many of the selected packaging companies. Mondi, for example, acknowledged that 'the production of paper and pulp is water intensive so we manage water wisely and responsibly. Wherever possible and economically feasible, we recycle water to conserve this important resource.' The company recognised that 'the cost of the water we use and the treatment of effluent from our production processes can be significant and uncertainties over the availability of water in some of the countries we operate can be a risk factor' and claimed that 'given its importance to our business and the communities in which we operate, we use water wisely and efficiently and we treat it responsibly at all times.' More specifically the company reported that in recent years its approach to water risk management has focused on conducting water impact assessments of all its forest operations and its pulp and paper mills and that these assessments have helped to mitigate water risks and to put in place measures to manage future risks. Further, the company reports that the water used in the production process is treated in waste water treatment plants before being released back into the natural environment and that it monitors and manages a number of key indicators, in particular chemical oxygen demand and absorbable organic halogens, and discharge water quality from its pulp and paper mills.

Waste management is seen to be an important element in many of the selected packaging companies sustainability plans and programmes. Ball Corporation, for example, outlined its 'waste strategy' as focusing on 'systematically reducing the amount of waste generated, eliminating waste sent to landfill and increasing recycling rates.' At the same time the company argued that because the classifications of waste and waste disposal methods vary from one country to another, reporting on accurate waste data in a timely and consistent manner can be a difficult task. Nevertheless, the company reports that each of its manufacturing plants tracks waste generation on a monthly basis and that this helps to identify the major opportunities to reduce waste and to divert it from landfill. Amcor reported on becoming a member of the 'Trash Free Seas Alliance', which looks to create solutions to the problem of marine debris and that the company is part of 'Project Reflex', a UK based programme which is looking to evaluate the recyclability of films and laminates through innovative product designs and recycling technologies, with the goal of creating a circular economy for flexible packaging within the country.

In reviewing the social dimensions of sustainability being addressed by the selected packaging companies a number of themes can be identified, including, 
human rights and labour practices, the health, wellbeing and safety of employees, diversity and equality of opportunity, employee representation and association, links with local communities and charitable donations. Amcor, for example, emphasised its 'strong focus on human rights' and reported that all its employees are required to receive, read and acknowledge the 'Amcor Code of Conduct and Ethics Policy' in their local language as part of their induction process. Further the company argued that its commitment to human rights and responsible labour practices is reflected in its membership of a number of independent global monitoring organisations. Ball Corporation stressed that because people are our most valuable resource maintaining safe and healthy work environment is and will remain a top priority.' The company's focus is on 'continuous improvement', on 'regularly checking the effectiveness of plant programmes through internal audit' and on 'enabling employees to take ownership of their safety and the safety of their colleagues.'

Mondi argued that 'it is difference in people-not uniformity that is key to Mondi's success' and that 'the geographic, cultural and personal diversity of the business is one of our greatest strengths.' More specifically the company reported 'we have a zero tolerance policy towards discrimination and harassment in our operations and we provide equal opportunities for all employees irrespective of origin, nationality, disability or gender' and that it looked to 'create an inclusive environment where differences are respected and valued.' Westrock reported that it 'provides employees with opportunities to enhance their knowledge and skills' and argued that by 'providing training and career development programmes we improve employee engagement at work resulting in greater job satisfaction for our co-workers and better results for the company and our stakeholders. ' Mondi reported compliance with all applicable national laws and industry standards on working hours, on promoting culture that fosters workplace flexibility and a work/life balance and not tolerating any forms of child labour in its operations or supply chain. Further, the company reported that it respected the rights of all employees to form and join trade unions and to take part in collective bargaining.

A number of the selected packaging companies reported on their commitment to, and links with, local communities and their charitable donations. Amcor, for example, stressed its commitments to 'supporting the communities where we live and work' and that 'we continually work to strengthen our engagement within communities in which Amcor operates.' More specifically the company reported that since the launch of the 'Amcor Community Program' it has invested over US \$ 1 million in programmes to increase access to food and essential products, reducing the environmental impact of packaging and educating people about how responsible packaging contributes to a more sustainable future. Under the banner 'Giving back is in Our Nature', International Paper reported on a number of global projects it supported either through donations or employee volunteering programmes. These projects included employee volunteering at a dam construction site in Tantikonda, near one of the company's paper mills in India, and providing food to children in need in Nairobi through the 'World Food 
Program USA' and empowering low income young students in Tres Lagoas in Brazil.

Economic issues generally received more limited explicit coverage in the sustainability reports and information posted by the selected packaging companies. Many companies report on economic issues indirectly, mentioning the creation of employment opportunities and supplier relationships, for example, as part of wider commentaries on sustainability. One of the selected companies, Stora Enso, explicitly identified an 'Economic Agenda' within its sustainability report. This agenda embraced three sets of issues, namely, customers, supplier and investors. In prefacing its commentary on customers, for example, the company argued that increasing global consumer demand for sustainability is encouraging companies and brand owners to provide smart and safe solutions to meet everyday needs.' The company claimed to be 'developing our expertise in renewable materials to meet customers' needs through products with high sustainability performance', to 'work actively together with our customers to improve the material efficiency and environmental impact of our products and related production processes' and to 'regularly measure customer satisfaction.' In addressing the issue of investors Stora Enso recognised the tensions between the growth in the number of socially responsible investors and shareholder demands for financial profits from their investments and outlined how it looked to manage the challenges posed by such tensions and stressed the importance of timely and transparent communication with shareholders on environmental, social and governance issues.

Secondly, there are variations in the nature of the reporting process. There was little or no uniformity in the character and style of the sustainability reports published by the selected packaging companies and the reports varied in length. Thus while the Mondi and Smurfit Kappa reports ran to 112 pages and 100 pages respectively, the International Paper sustainability report was 34 pages and Amcor's report was 28 pages. While some of the sustainability reports provided detailed structured narratives others offered a lighter and less detailed commentary. While all the selected companies included some data on environmental and social issues within their sustainability reports the scope and time scale and geographical coverage varied considerably. Thus while Amcor, for example, just published some simple time series data on recorded injuries and time lost through injuries across the whole company, the Stora Enso sustainability report included data on fossil carbon dioxide emissions, process water discharges, chemical oxygen demands and processed waste to landfill across a number of countries and plants in Northern and Western Europe. The leading packaging companies' sustainability reports often looked to illustrative general narrative with cameo 'case studies' and with graphs, diagrams and photographic images.

Four of the eight selected packaging companies which produced sustainability reports, namely Amcor, Smurfit Kappa, Ball Corporation and Stora Enso, made reference to external recognition and/or reporting guidelines. Smurfit Kappa, Stora Enso and Ball Corporation reported that their sustainability reports had been prepared in accordance with GRI G4 guidelines, Amcor drew attention to 
the external recognition for their sustainability achievements and reported 'we are proud that global and regional sustainability indices recognise Amcor for our performance' and that these indices included 'the Dow Jones Sustainability Index, sustainability world Index, the CDP Climate Disclosure Index for Australia and The FTSE4Good Index.' Only three of the leading packaging companies, namely Smurfit Kappa, Mondi and Sealed Air looked to introduce the concept of materiality into its sustainability reporting process. None of the other selected companies made explicit reference to the role of internal and external stakeholders in identifying the sustainability issues addressed in their sustainability reports

In constructing its materiality matrix Smurfit followed the approach recommended by the GRI in that the matrix axis focused on significance of economic, environmental and social impacts' and 'influence on stakeholder's assessments and decisions' (Global Reporting Initiative 2011, p.8 ).In contrast while Sealed Air incorporated materiality into its sustainability reporting process for the first time in 2014, the two axes that Sealed Air used to draw up its materiality matrix, were 'increasing importance to external stakeholders' and increasing importance to internal stakeholders. This in turn would seem to favour corporate business continuity goals, rather than more general environmental, social and economic goals. More specifically, this corporate privileging of sustainability goals might be seen to be reflected in the lower status the matrix attached, for example, to threats to biodiversity, environmental impacts of transport and public policy and engagement, with higher status being accorded to ethical business practice, product safety and quality and employee safety.

Four of the selected packaging companies, namely Ball Corporation, Smurfit Kappa, Mondi and Stora Enso, commissioned independent external assessment as an integral part of their sustainability reporting process. The assurance assessments covered a relatively small percentage of the issues on which the companies reported. The Stora Enso, assurance report, which was conducted by Deloitte \& Touche, for example, covered only the company's direct and indirect fossil carbon dioxide emissions and here Deloitte \& Touche offered the limited assurance concluded that 'nothing has come to our attention that causes us to believe that information subject to the assurance engagement is not prepared in all material aspects, in accordance with the Sustainability Reporting guidelines G4.' The Ball Corporation commissioned external assurance for just six of the GRI 4 disclosures listed in their sustainability report. The disclosures that were subject to external assurance were both direct and indirect energy use, both direct and indirect greenhouse gas emission, total water withdrawn by source and total weight of waste by type and method of disposal. 


\section{Discussion}

While the findings revealed that while the majority of the leading packaging companies publicly recognised the impacts their businesses have on the environment, on society, and to a lesser extent, on the economy, there are variations in the character, extent and detail of the reporting process. The packaging companies' generally idiosyncratic approach to reporting on sustainability makes it difficult to make any meaningful comparisons between companies or to attempt any evaluation of the contribution the leading players within the industry are making towards the achievement of sustainability targets at national or international levels. This is not a problem per se, in that companies have no statutory obligation to report on sustainability, but in reviewing the leading packaging companies' current approach to sustainability, four sets of issues of issues merit discussion and reflection.

Firstly, while the majority of the leading packaging companies emphasised their commitment to sustainability they can be seen, individually and collectively, to have constructed a specific definition of the concept. This definition is primarily built around business efficiency and cost savings and is driven more by business imperatives than by any concern with sustainability. Thus, while many of the environmental agendas addressed by the selected companies are designed to reduce greenhouse gas emissions, energy, water consumption and waste, for example, they also serve to reduce costs. In a similar vein the packaging companies' commitments to their employees, focusing for example upon good working conditions, health and safety at work and training all help to promote stability, security, loyalty and efficiency within the workforce.

The leading packaging companies might thus be seen to have constructed sustainability agendas, which are driven primarily, though not necessarily exclusively, by their own commercial interests. The accent being on efficiency gains across a wide range of economic, social and environmental issues rather than on maintaining the viability of natural ecosystems and reducing demands on finite natural resources. More generally there is the argument that corporate sustainability reporting can obscure the effect of corporate activity on the external environment and that in persuading investors that corporate activity is sustainable this can have the effect of reducing the cost of capital for the company with investors being 'misled into thinking that the level of risk involved in their investment is lower than it actually is' (Aras and Crowther 2009, p. 279). In a similar vein Banerjee (2008, p.51) has argued that 'despite their emancipatory rhetoric, discourses of corporate citizenship, social responsibility and sustainability are defined by narrow business interests and serve to curtail the interests of external stakeholders.'

Earlier in this paper the authors suggested that corporate sustainability was also increasingly seen to incorporate the concept of the creation of shared value. While the leading packaging companies do not explicitly employ the term shared value in their sustainability reports a number of their sustainability commitments; to employees and communities; to investing in social welfare; 
and to environmental stewardship; are expressed within the paradigm of shared value. However, Crane et al. (2014) identified a number of weaknesses and shortcomings in the creation of the shared value model. More specifically, Crane et al. (2014) argued that the model did not take account of the potential tensions between economic and social goals, that it was naïve about the challenges involved in business compliance and that it was grounded in a shallow view of the role of companies within society. In examining the first of these concerns, for example, Crane et al. (2014, p136) suggested that 'many corporate decisions related to social and environmental problems, however creative the decision-maker may be, do not present themselves as potential win-wins, but rather manifest themselves in terms of dilemmas.' As such Crane et al. (2014) argued that such dilemmas represent continuous struggles between companies and their stakeholders over limited resources and recognition. In justifying their assertion Crane et al. (2014, p. 140) argued that the model seeks to 'rethink the purpose of the corporation without questioning the sanctity of corporate self-interest.'

Secondly materiality and assurance received limited attention from the leading packaging companies. There was little reference, for example, to how material issues were identified by the companies or to the role of a range of stakeholders in the identification process. As such the sustainability reports and information posted by the selected packaging companies might be seen to represent the executive management's approach to sustainability rather than the potentially wider sustainability agendas and concerns of the company's stakeholders. Two of the three selected packaging companies that employed a matrix approach to identify material issues did so, as outlined earlier, in a way that might be seen to favour corporate business continuity goals, rather than more general environmental, social and economic goals. McElroy (2011, webpage), for example, claimed that this approach 'essentially cuts out consideration of what are arguably the most material issues' namely 'the broad social, economic and environmental impacts of an organisation regardless of how they relate to a particular business plan or strategy.' At the same time, a number of the companies did not report on commissioning independent external assurance and this can be seen to reduce the credibility, integrity and reliability of the leading packaging companies' sustainability reporting processes. That said the leading packaging companies are large and dynamic organisations and capturing and storing comprehensive information and data throughout the supply chain in a variety of geographical locations and then providing access to allow external assurance is a challenging and a potentially costly venture. Currently the majority of the selected packaging companies choose not to publicly pursue such an exercise.

Thirdly, with an eye to the future, while the sustainability reports and information posted by a number of the selected packaging companies are couched within the paradigm of continuing growth and business expansion there are tensions between continuing growth, and sustainability. These packaging companies' commitments to growth are evidenced in a number of ways. Smurfit Kappa, for example, stressed its approach to sustainable 
development 'has delivered consistent growth.' In a similar vein Mondi emphasised its belief that its approach to sustainable development 'provides a strong foundation for future sustainable profitable growth.' In his 'CEO Perspective' to Ball Corporation's sustainability report, John A Hayes, Chairman, President and Chief Executive Officer, the company was committed to be more efficient, more cost effective and to set new standards in sustainable growth. However there are fundamental questions about whether continuing economic growth is compatible with sustainable development. On the one hand some critics would suggest that continuing economic growth and consumption, dependent as it is, upon the seemingly ever increasing depletion of the earth's natural resources, is fundamentally incompatible with sustainability. Higgins (2013), for example argued continuing economic growth is diametrically opposed to sustainability

On the other hand the dominant corporate argument is that continuing economic growth will inevitably be accompanied by the more efficient use of resources. This trend, which is seen as either relative or absolute decoupling (relative decoupling refers to using fewer resources per unit of economic growth while absolute decoupling refers to a total reduction in the use of resources), underpins many conventional definitions of sustainability and the vast majority of current corporate sustainability strategies and programmes. However decoupling is seen by some critics to be an elusive goal and a number of commentators (e.g. Conrad and Cassar 2014; Wiedmann et al. 2015) have called into question the belief that countries can effectively grow their way out of environmental problems. Arguably more radically, Jackson (2009, p. 57) concluded a discussion of what he described as 'the myth of decoupling' by arguing that it is entirely fanciful to suppose that deep emission and resource cuts can be achieved without confronting the structure of market economies.'

At the same time a number of the leading packaging companies reported on how their commitment to innovation and to harnessing a wide range of new developments in technology would be vitally important to improving efficiency across the sustainability spectrum and in helping to deliver sustainable growth. Sealed Air, for example, emphasised its role as 'a leading innovator' and that 'we don't just provide product innovations; we create partnerships with our customers through our services and knowledge-based solutions that help them meet their own aggressive sustainability requirements and goals.' More generally, a number of commentators (e.g. Clark and Dickson 2003) have stressed the importance of advances in science and technology in providing greater efficiency and thus in promoting sustainable development. However, while Schor (2005, p.310) recognised that advocates of technological solutions argue that more intelligent design and technological innovation can dramatically reduce or even stop the depletion of ecological resources' he argued that such approaches 'fail to address increases in the scale of production and consumption, sometimes even arguing that such increases are not unsustainable if enough natural-capital-saving technical change occurs.'

Finally, the concept of sustainable consumption, which Cohen (2005, webpage) has described as 'the most obdurate challenge for the sustainable 
development agenda' receives limited attention in the sustainability reports and information posted by the leading packaging companies. In arguing that 'Europe must take the lead in exploring a new model of consumption which does not compromise the needs of others or of future generations, nor damage the environment', The European Environment Agency (2012, webpage) branded 'unsustainable consumption' as 'the mother of all environmental issues.' That said, within Europe there is little evidence of genuine consumer appetite for sustainable consumption and here the European Commission's (2012) belief that sustainable consumption is a step backwards in the desire to improve living standards and the quality of life, resonates.

This view is supported by Reisch et al. (2008, p.2) who argued that, although moving towards sustainable consumption is a major policy agenda, 'growth of income and material throughput by means of industrialization and mass consumerism remains the basic aim of western democracy.' More critically, Castro (2004) has questioned the very possibility of sustainable development under capitalism and argued that economic growth relies upon the continuing and inevitable exploitation of both natural and social capital.

\section{Conclusions}

The majority of the leading global packaging companies publicly reported on their commitments to sustainability and on their achievements in meeting such commitments and a number of conclusions can be systematically identified from the current exploratory examination of the reporting process. The selected sustainability reports include a wide range of environmental and social agendas and as such reflects van Marrewick and Werre's (2002) definition of corporate sustainability outlined earlier. Further a number of the selected companies argued that by integrating sustainability into their businesses, they were creating sustainable value, were better placed to provide long term growth and financial security for all stakeholders and to enhance their market position and reputation. This would, in turn, suggest that for the leading packaging companies corporate sustainability can be seen as a 'core consideration' (KPMG 2012, webpage) driving company strategies. At the same time a number of the selected companies' sustainability reports include commitments, for example, to their employees, to local communities and to environmental stewardship which reflect the spirt of the concept of the creation of shared value (Porter and Kramer 2011) as outlined earlier in this paper.

However the authors would argue that the leading packaging companies' definitions of, and commitments to, sustainability can be interpreted as being driven as much by business imperatives as by any fundamental commitments to corporate sustainability or the creation of shared value. More specifically the authors would argue that the accent currently appears to be on making efficiency gains across a wide range of economic, social and environmental issues rather than on maintaining the viability and integrity of natural ecosystems and on reducing demands on finite natural resources. Such criticism notwithstanding, 
the authors would argue that the sustainability reports published by the leading players in the packaging industry compare favourably with those produced by the world's leading retailers (Jones et. al. 2011) and those produced by the major companies elsewhere in the consumer goods and services industries (e.g. Jones et al. 2012; Jones et al 2014). More critically the authors suggest that the leading packaging companies' commitments to sustainability are couched within existing business models centred on continuing growth and consumption and that current policies might be viewed as little more than genuflections to sustainability. As such the selected packaging companies are, at best, pursuing a 'weak' rather than a 'strong' model of sustainability (Hudson 2005). This, in turn, reflects Roper's (2012, p. 72 ) belief that weak sustainability represents ' $a$ compromise that essentially requires very little change from dominant economic driven practices but effectively works to defuse opposition, increase legitimacy and allow business as usual.'

Looking to the future and in the face of growing media, investor, customer, pressure group and government scrutiny, all packaging companies may seek to further develop and adopt a more rigorous and transparent approach to, their sustainability reporting. Here the leading players in the packaging industry may want to address how they can continue to reflect on corporate approaches to sustainability, on the development of such approaches over time and on how to bring greater value and transparency to the reporting process. At the same time, future academic research agendas might usefully build on the current paper by focusing on a number of avenues of enquiry. These include, for example, market research into customers' perceptions of the environmental and social impacts of the packaging industry and its impact on purchasing behaviour, investigations into if, and how, packaging companies look to manage sustainability issues within the supply chain and if and how greater transparency in the sustainability reporting process is reflected in corporate investment and profitability.

\section{References}

Amini, M. and Bienstock, C.C. (2014) Corporate sustainability: an integrative definition and framework to evaluate corporate practice and guide academic research. Journal of Cleaner Production 76 (1): 12-1

Aras, G. and Crowther, D. (2008) Governance and Sustainability: An investigation into the relationship between corporate governance and corporate sustainability. Management Decision 46 (3): 433-448

Aras, G. and Crowther, D. (2009) Corporate Sustainability Reporting: A Study in Disingenuity' Journal of Business Ethics 79 (1): 279-288

ASD (2013) History of Packaging. Available at: http://www.ambalaj.org.tr/en/envi ronment-history-of-packaging.html

Banerjee, S. B. (2008) Corporate Social Responsibility: The Good, the Bad and the Ugly. Critical Sociology 34 (1): 51-79

Castro, C. (2004) Sustainable Development: Mainstream and Critical Perspectives. Organisation and Environment 17 (2): 195-225. 
Clark, W.C. and Dickson, N.M. (2003) Sustainability science: The emerging research program. Proceedings of the National Academy of Sciences in the United States of America 14 (4): 8059-8061,

Cohen, M.J. (2005) Sustainable consumption in a national context; an introduction to the symposium. Available at: http://ejournal.nbii.org/archives/vol1iss 1/0410-008. cohen.htmll

Conrad, E. and Cassar, L.F. (2014) Decoupling Economic growth and Environmental Degradation: Reviewing Progress to Date in the Small Island State of Malta. Sustainability 6: 6729-6750,

Crane, A., Palazzo, G., Spence, L.J. and Matten, D. (2014) Contesting the Value of Creating Shared Value. California Management Review 56 (2): 130-154

CSR Reporting (2011) Transparency is the Key to Sustainability. Available at: http:// csr-reporting.blogspot.co.uk/2011/09/transparency-is-key-to-sustainability.html

de Grosbois, D. (2016) Corporate Social Responsibility Reporting in the Cruise Tourism Industry: A Performance Evaluation using a New Institutional Theory Based Model. Journal of Sustainable Tourism 24 (2): 245-269

Diesendorf, M. (2000) Sustainability and Sustainable Development, In: Dunphy, D., Beneveniste, J., Griffiths, A. and Sutton, P. (eds) Sustainability: The corporate challenge of the $21^{\text {st }}$ century. Sydney: Allen and Unwin,

Dyllick, T. and Hockerts, K. (2002) Beyond the Business Case for Corporate Sustainability. Business Strategy and the Environment 11 (2): 130-141.

EY (2013) Unwrapping the packaging industry. Available at: http://www.ey.com/Pub lication/vwLUAssets/Unwrapping_the_packaging_industry_\%E2\%8 2017)0\%93 _seven_factors_for_success/\$FILE/EY_Unwrapping_the_packaging_industry__seven_success_factors.pdf

European Commission (2012) Policies to Encourage Sustainable Consumption. Available at: http://ec.europa.eu/environment/archives/eussd/pdf/report_2208201 2.pdf

European Environment Agency (2012) Unsustainable consumption - the mother of all environmental issues. Available at: http://www.eea.europa.eu/highlights/unsustai nable-consumption-2013-the-mother

Europen (2011) Packaging and Sustainability. Available at: http://www.europen-pac kaging.eu/sustainability/packaging-environment.html

Garriga, S. and Mele, D. (2004) Corporate Social Responsibility Theories: Mapping the Territory. Journal of Business Ethics 53 (1): 51-71

Global Reporting Initiative (2011) Sustainability Reporting Guidelines. Available at: https://www.globalreporting.org/resourcelibrary/G3.1-Guidelines-Incl-TechnicalProtocol.pdf

Gruber, U. (2013) Sustainability: a Cultural History. (Translated by Ray Cunningham), Cambridge: Green Books.

Guthrie, J. and Abeysekera, I. (20016) Content analysis of social environmental reporting: what is new? Journal of Human Resource Costing and Accounting 10 (2): 114-126

Higgins, K.L. (2013) Economic growth and sustainability- are they mutually exclusive. Available at: https://www.elsevier.com/connect/economic-growth-and-sustainabi lity-are-they-mutually-exclusive

Hudson, R. (2005) Towards sustainable economic practices, flows and spaces: or is the necessary impossible and the impossible necessary? Sustainable Development 13 (4): 239-252.

International Union for Conservation of Nature and Natural Resources (1980) World Conservation Strategy. Available at: https://portals.iucn.org/library/efiles/docu ments/wcs-004.pdf 
Jackson, T. (2009), Prosperity without growth? Available at: http://www.sd-com mission.org.uk/data/files/publications/prosperity_without_growth_report.pdf

Jones, P., Comfort, D. and Hillier, D. (2011) 'Sustainability in the Global Shop Window', International Journal of Retail and Distribution Management, Vol. 39, No. 4, pp. 256-271

Jones, P. Comfort, D. and Hillier, D. (2012) 'Corporate Social Responsibility on the Catwalk', Journal of Business and Retail Management Research, Vol. 7, No. 1, pp. 118-129

Jones, P., Hillier, D. and Comfort, D. (2014) 'Sustainability in the global hotel industry', International Journal of Contemporary Hospitality Management, Vol. 26, No. 1, pp.5-17

KPMG (2012) Corporate Sustainability: A Progress Report. Available at: http://www.sus tainabilityexchange.ac.uk/files/corporate-sustainability-a-progress-report_1.pdf

Lozano, R. Carpenter, A. and Huisingh, D. (2015) A review of theories of the firm and their contributions to corporate sustainability. Journal of Cleaner Production 106: 430-442

McElroy, M. (2011) Are Materiality Matrices Really Material? Available at: http://www. sustainablebrands.com/news_and_views/articles/are-materiality-matrices-reallymaterial

Nestle (2017) Building on Creating Shared Value. Available at: http://www.nestle. $\mathrm{com} / \mathrm{csv} /$ what-is-csv

Newell, G. (2008) The strategic significance of environmental sus trainability by Australian-listed property trusts. Journal of Investment Property and Finance 37 (2): 205-209.

Persistence Market Research (2015) The Global Packaging Market Growth is governed by numbers of Direct and Indirect Factors. Available at http://www. persistencemarketresearch.com/article/packaging-market.asp

Porter. M. E. and Kramer, M. R. (2011) Strategy and society: the link between competitive advantage and corporate social responsibility. Harvard Business Review 87: 78-92

PricewaterhouseCooopers (2010) Sustainable Packaging: Threat or Opportunity. Available at: https://www.pwc.com/gx/en/forest-paper-packaging/pdf/sustainable -packaging-threat-opportunity.pdf

Raconteur (2013) Facing the Environmental Challenges of Packaging. Available at: https://www.raconteur.net/business/facing-the-environmental-challenges-of-packa ging

Reisch, L., Spash, C. L. and Bietz, S. (2008) Sustainable Consumption and Mass Communication: A German Experiment. Available at: http://www.csiro.au/files/ files/pm9m.pdff

Roper, J. (2012) Environmental risk, sustainability discourses and public relation. Public Relations Inquiry 1 (1): 69-87

Saunders, M., Lewis, P. and Thornhill, A. (2009) Research Methods for Business Students. Harlow: Prentice-Hall,

Schor, J. B. (2005) Prices and quantities: unsustainable consumption and the global economy. Ecological Economics 55: 309-320,

Sustainability (2014) See Change: How Transparency Drives Performance. Available at: http://www.sustainability.com/library/see-change\#.V0KxO032aUk

Technavio (2016) Top 20 Companies in the Global Packaging Market. Available at: https://www.technavio.com/blog/top-20-companies-global-packaging-market

United Nations Environment Programme (2013) Frequently Asked Questions on Corporate Sustainability Reporting. Available at: https://www.globalreporting. org/resourcelibrary/GoF47Para47-FAQs.pdf 
van Marrewick, M. and Werre, M. (2002) Multiple Levels of Corporate Sustainability. Available at: http://vanmarrewijk.nl/pdf/021206131353.pdf

Wiedmann, T.O., Manfred, S., Lenzen, M., et al. (2015) The Material Footprint of Nations. Proceedings of the National Academy of Sciences 112 (20): 6271 -6276

World Commission on Environment and Development (1987) Our Common Future. Available at: http://www.un-documents.net/ocf-02.htm 
